\title{
Frailty syndrome in Brazilian older people: a population based study
}

\author{
Síndrome de fragilidade em idosos brasileiros: um estudo de base \\ populacional
}

Rita de Cássia Guedes (https://orcid.org/0000-0001-8490-1882) ${ }^{1}$

Rosangela Dias (https://orcid.org/0000-0002-1027-7746) ${ }^{2}$

Anita Liberalesso Neri (https://orcid.org/0000-0002-6833-7668) ${ }^{3}$

Eduardo Ferriolli (https://orcid.org/0000-0002-5028-2451) ${ }^{4}$

Roberto Alves Lourenço (http://orcid.org/0000-0003-0838-1285) ${ }^{5}$

Lygia Paccini Lustosa (https://orcid.org/0000-0002-0919-1320) ${ }^{1}$

${ }^{1}$ Centro Universitário de Belo Horizonte. Av Professor Mário Werneck 1685, Buritis. 30575180 Belo Horizonte MG Brasil.rita.guedes@ animaeducacao.com.br ${ }^{2}$ Departamento de Fisioterapia, Universidade Federal de Minas Gerais. Belo Horizonte Minas Gerais Brasil.

${ }^{3}$ Departamento de Gerontologia, Faculdade de Ciências Médicas, Universidade Estadual de Campinas. Campinas SP Brasil.

${ }^{4}$ Departamento de Clínica Médica, Faculdade de

Medicina de Ribeirão Preto, Universidade de São Paulo. Ribeirão Preto SP Brasil.

${ }^{5}$ Policlínica Piquet Carneiro, Universidade do Estado do Rio de Janeiro. Rio de Janeiro RJ Brasil.

\begin{abstract}
This article aims to categorize elderly non-frail (NF), pre-frail (PF) and frail (FF) as to fast and slow gait speed. Compare NF, PF and FF, and analyze associations between fast or slow gait speed with clinical, functional and mental factors. 5,501 elderly (65 years or over; to the Frailty in Brazilian Older People Study), classified as NF, PF and FF (Fried's frailty phenotype) and, in relation to fast gait speed $(\geq 0.8 \mathrm{~m} / \mathrm{s})$ and slow $(<0.8 \mathrm{~m} / \mathrm{s})$. Age, sex, body mass index, muscular strength, advanced, instrumental and basic activities of daily living, falls, fear of falling and depressive symptoms were evaluated. Logistic regression analysis investigated associations between variables. The proportion of the slow elderly increased with fragility ( $N F=12.39 \%, P F=37.56 \%, F F$ $=88.83 \%, p<0.01)$. Be woman, performance in activities of daily living, muscle strength and fall were associated with fragility syndrome. The association between frailty and adverse health outcomes reinforces its primacy as an indicator of the functional health of the elderly. Functional capacity, muscular strength, and falls should be evaluated considering their potential for reversibility. Key words Aged, Gait, Elderly health, Frail elderly
\end{abstract}

Resumo $O$ artigo tem por objetivos categorizar idosos não frágeis (NF), pré-frágeis (PF) e frágeis (FF) quanto à velocidade rápida e lenta de marcha. Compara NF, PF e FF, e analisa associações entre velocidade de marcha rápida e lenta com fatores clínicos, funcionais e mentais. 5.501 idosos (65 anos ou mais; Estudo de Fragilidade em Idosos Brasileiros - Rede Fibra), classificados em NF, PF e FF (fenótipo de fragilidade de Fried) e, quanto a velocidade de marcha rápida $(\geq 0.8 \mathrm{~m} / \mathrm{s})$ e lenta $(<$ $0.8 \mathrm{~m} / \mathrm{s}$ ). Avaliou-se idade, sexo, indice de massa corpórea, força muscular, atividades instrumentais, básicas e avançadas de vida diária, quedas, medo de quedas e sintomas depressivos. Análise de regressão logística para verificar associação entre variáveis. A proporção de idosos lentos aumentou com a fragilidade $(N F=12,39 \%, P F=37,56 \%$, $F F=88,83 \%, p<0,01)$. Ser mulher, desempenho nas atividades de vida diária, força muscular e relato de quedas associou-se com a fragilidade. A associação entre fragilidade e eventos adversos de saúde reforçou sua importância em ser um indicador da saúde funcional dos idosos. Capacidade funcional, força muscular e ocorrência de quedas devem ser avaliados, considerando seu potencial de reversibilidade.

Palavras-chave Idoso, Marcha, Saúde do idoso, Idoso frágil 


\section{Introduction}

The Frailty Syndrome (FS) is able to predict adverse health outcomes. The frail elderly have a greater chance of developing disability, being hospitalized or institutionalized, experiencing recurrent falls and death ${ }^{1,2}$. Among the conditions associated with frailty, it highlights functional dependence, generalized muscular weakness, fear of falling, depression and cognitive impairment ${ }^{3}$. In addition, being female, presenting comorbidities and disabilities and aging itself contribute to the establishment of $\mathrm{FS}^{4}$.

Frailty results from multisystem deficiencies that generate different changes of normal aging process. Fried et al. ${ }^{5}$ defined frailty as a decrease in reserve and resistance to stressors, leading to a reduction in the homeostatic capacity ${ }^{5}$. In this concept, the physical components of frailty are detached and interact in cycle form, relying on the tripod sarcopenia, neuroendocrine dysregulation and immunological changes ${ }^{2}$. Thus, the frailty phenotype, an operational definition proposed by Fried et al. ${ }^{5}$, was created with the purpose to translate the manifestations of the frailty cycle, consisting of weight loss, exhaustion, low level of physical activity, muscle weakness and slow gait. It classifies the elderly as frailty, pre-frailty and not frailty, according to the number of positive items ${ }^{5}$.

One of the phenotype items is the usual gait speed (GS) that can predict multiple health outcomes in the elderly population by reflecting the interaction of various organic systems $s^{6,7}$. With aging, the availability of body energy decreases and energy needs for independent living increase, compromising the body's homeostatic balance ${ }^{8}$. The reduction of the GS is recognized as an adaptive behavior that indicates the inadequate functioning of the body systems, suggesting that each individual selects the GS that best adapts to their functional reserves ${ }^{9}$. Several studies have proved their capacity to predict many adverse health outcomes. Slow elderly demonstrated 2.5fold greater chance of presenting adverse health outcomes $^{6,7,10}$. Increase in the GS of at least 0.1 $\mathrm{m} / \mathrm{s}$ can predict well-being and reduce by $12 \%$ the risk of death ${ }^{1,11,12}$. In affluent countries, the cutoff point of $0.8 \mathrm{~m} / \mathrm{s}$ appears to be the most sensitive and used value for health outcomes ${ }^{10,12}$. Although GS is a predictor of adverse health events, there is still no data on how the Brazilian elderly behave. In addition, identifying factors associated with being slower or faster during walking may increase knowledge regarding risk factors for
Brazilian elderly. Thus, it is believed that a deeper understanding of the factors associated with GS in the three levels of frailty may contribute to the development of adequate strategies for the evaluation, prevention and rehabilitation of the elderly. Therefore, the objectives of this study were to categorize elderly non-frail, pre-frail and frail elderly in relation to fast and slow gait speed, to compare elderly non-frail, pre-frail and frail, as well as to analyze the associations between fast or slow GS with clinical, demographic, functional and mental factors.

\section{Methods}

The Frailty in Brazilian Older People Study $(\text { Fibra-BR })^{13,14}$ was designed as a crosssectional, population-based, multicenter and multidisciplinary study conducted in 17 cities from all five Brazilian geographical regions with diverse human development indexes. The cities were chosen by the convenience of research coordinators and the sample in each city was selected according to probabilistic sampling strategy among community-dwelling older adults ( 65 years and over) stratified by sex and age. In each city, the sample was determined based on a method calculation to guarantee local representativeness. Each region of the municipality, streets were randomly chosen, and in them all residences were visited in search of the elderly. Participants interviewed in each sector varied according to the concentration of the elderly in that area, as determined by the Census of the Brazilian Institute of Geography and Statistics of 2000, totaling 6,762 elderly people. However, the participants whose data concerning the phenotype of frailty and gait speed were missing were excluded. The evaluation was done only once and applied by previously trained interviewers. In all cities, professional experts in the field of gerontology trained the evaluators for six months.

Elderly people aged 65 and over, regardless of sex or race, were invited to participate in the study. Individuals with diseases or sequelae that prevented the tests were excluded; wheelchair users; bedridden or terminally elderly; patients with severe vision and hearing deficits, and those who did not reach the score according to schooling in the Mini-Mental State Examination ${ }^{15}$. The Research Ethics Committee approved the project and all participants signed a consent form.

The frailty was operationalized according to the scale proposed by Fried et $a .^{5}$ considering 
the following criteria: unintentional weight loss evaluated by self-report reduction of 4.5 $\mathrm{kg}$ or more or $5 \%$ of body weight; exhaustion investigated by questions 7 and 20 of the depression scale of Center for Epidemiological Studies ${ }^{16}$; level of physical activity measured by the Minnesota Leisure Time Physical Activity Questionnaire ${ }^{17}$; muscle strength through hand grip strength (HGS) measured with Jamar manual dynamometer and gait speed time determined by the time spent to cover $4.6 \mathrm{~m}$, plus initial and final $2 \mathrm{~m}$, corresponding to the phases of acceleration and deceleration of gait. The HGS values and gait time were adjusted by the 20th and 80th percentile of the sample, respectively. According to the score in the five components, the elderly were considered frail when they met three or more criteria; pre-frail in the presence of one or two criteria and not frail in the absence of them. The gait speed (GS) (m/s) was calculated by dividing the distance traveled $(4.6 \mathrm{~m})$ by the time spent to travel it. GS was used as a categorical variable, using the cutoff point of $0.8 \mathrm{~m} / \mathrm{s}$, which is considered the most sensitive value for health outcomes ${ }^{1}$.

The independent variables were evaluated by a multidimensional inquiry standardized by the Fibra Study and grouped into demographic and clinical variables (age, sex, report and number of falls in the last year, body mass index (BMI) and HGS); functional variables (functional performance assessed by the Advanced Activities of Daily Life Scale (AADL) ${ }^{18}$, considering the sum of the activities that the elderly have failed to perform (high score means worse functionality); Instrumental Activities of Daily Living (IADL) ${ }^{19}$, evaluated by the Lawton scale (high score means better functionality) and Basic Activities of Daily Living (BADL) evaluated by the scale KatzBrasil $^{20}$ (high score means better functionality); psycho affective variables (sense of self-efficacy to prevent falls, measured by the Brazilian version of the Falls Efficacy Scale International (FESI-Brazil) ${ }^{21}$ (high score means high risk of falls); depressive symptoms evaluated by the short version of the Geriatric Depression Scale (GDS$15)^{22}$ (high score means worse mental function).

The sample was divided into three groups according to the frailty phenotype: non-frail group (NF), pre-frail group (PF) and frail group (FF). In each group, elderly with a GS below $0.8 \mathrm{~m} / \mathrm{s}(\mathrm{GS}<0.8 \mathrm{~m} / \mathrm{s})$ were classified as slow and those with a GS equal to or greater than $0.8 \mathrm{~m} / \mathrm{s}$ (GS $\geq 0.8 \mathrm{~m} / \mathrm{s})$, classified as fast.

\section{Statistical analysis}

The sampling was performed according to the method of randomized sampling by clusters by area. In order to calculate the sample of each city, it was estimated the sample size necessary to have a population proportion of $50 \%$ of a given characteristic (value in which the sample size obtained was the maximum possible $(\mathrm{p}=0.50$; $\mathrm{q}$ $=0.50$ ), according to the age group of each of the cities was defined as the significance level of $5 \%$ (alpha $=5 \%, Z=1.96$ ), and the sampling error ranged from $3 \%$ to $5 \%$. For cities with more than one million inhabitants was set at 601 elderly people, to a $4 \%$ error.

Descriptive analyzes of the sample were performed, with mean and standard deviation values for numerical variable and percentage for categorical variables. All variables presented a normal distribution, evaluated by the Kolmogorov-Smirnov test. Differences between groups were evaluated by ANOVA tests with Tukey post-test and Chi-square test. Variables with p-value greater than 0.10 in bivariate analysis were not included into regression analysis. In the bivariate analysis, the Pearson correlation test was used between the gait speed variables and all the independent variables. Logistic regression models with forward criteria were plotted for each group, considering the dependent variable the GS categorized as $<0.8 \mathrm{~m} / \mathrm{s}$ and $\geq 0.8 \mathrm{~m} / \mathrm{s}$. These analyses aimed to estimate the effects of each independent variable on the chance of the elderly presenting themselves as slow when compared to fast elderly. It was calculated the odds ratio (OR) of each independent variable associated with the GS. There was no difference in the form of statistical procedure analyzes in the quantitative variables. All analyses were performed using the SPSS 17.0 statistical program; a significance level of $5 \%$ was considered.

\section{Results}

The study was attended by 5,501 communitydwelling elderly people from 17 Brazilian cities, with a mean age of $73.01 \pm 6.17$ years (CI95\%, $72.85 ; 73.17)$, of which $2,034(37.00 \%)$ were classified as non-frail; $2,822(51.30 \%)$ as pre-frail and $645(11.70 \%)$ as frail. The univariate analyzes showed statistically significant differences between the three groups in relation to all independent variables $(\mathrm{p}<0.05)$, except for BMI $(p>0.05)$ (Table 1). The mean GS of the total 
Table 1. Mean, standard deviation and frequency distribution of the clinical, demographic, functional and mental factors, comparing not frail, pre-frail and frail elderly and p-value.

\begin{tabular}{|c|c|c|c|c|c|}
\hline Characteristics & $\begin{array}{c}\text { Total } \\
\text { Sample } \\
(\mathrm{N}=5501)\end{array}$ & $\begin{array}{c}\text { Non Frail } \\
(\mathrm{N}=2034) \\
37,0 \%\end{array}$ & $\begin{array}{c}\text { Pre-Frail } \\
(\mathrm{N}=2822) \\
51,3 \%\end{array}$ & $\begin{array}{c}\text { Frail } \\
(\mathrm{N}=645) \\
11,7 \%\end{array}$ & p-value \\
\hline Age, years (SD) & $73.01(6.17)$ & $72.10(5.83)$ & $73.36(6.17)$ & $76.71(7.18)^{*} \mathfrak{E}$ & $<0.01$ \\
\hline Sex & & & & & $<0.01$ \\
\hline Male, n (\%) & $1862(33.80)$ & $750(36.90)$ & $937(33.20)$ & $177(27.40)$ & \\
\hline Female, $\mathrm{n}(\%)$ & $3639(66.20)$ & $1284(63.10)$ & $1885(66.80)$ & $468(72.60)$ & \\
\hline Falls in previous year, $\mathrm{n}(\%)$ & $1667(30.30)$ & $498(24.10)$ & $828(29.36)$ & $341(55.44)$ & $<0.01$ \\
\hline Number of falls (SD) & $1.30(0.9)$ & $0.30(1.12)$ & $1.33(0.98) ¥$ & $2.54(1.51)^{*} \mathfrak{E}$ & 0.01 \\
\hline $\mathrm{BMI}\left(\mathrm{kg} / \mathrm{m}^{2}\right)(\mathrm{SD})$ & $26.87(5.29)$ & $26.80(4.71)$ & $27.00(5.02)$ & $26.82(6.14)$ & 0.07 \\
\hline HGS (kgf) (SD) & $22.90(8.37)$ & $29.72(8.33)$ & $24.37(9.30) ¥$ & $14.63(7.48)^{*} \mathfrak{E}$ & $<0.01$ \\
\hline AADL (SD) & $3.25(3.87)$ & $2.73(1.81)$ & $3.04(2.05)$ & $3.99(2.47) \mathfrak{E}$ & $<0.01$ \\
\hline IADL (SD) & $19.14(2.31)$ & $20.70(1.29)$ & $19.59(2.09)$ & $17.14(3.56) \mathfrak{E}$ & $<0.01$ \\
\hline BADL (SD) & $0.20(0.67)$ & $0.10(0.32)$ & $0.13(0.35)$ & $0.37(0.90)^{\star \mathfrak{E}}$ & $<0.01$ \\
\hline FES-I - Brasil (SD) & $28.41(7.32)$ & $23.54(8.41)$ & $26.88(9.98)$ & $34.81(11.58)^{\star} \mathfrak{E}$ & $<0.01$ \\
\hline GDS (SD) & $7.65(1.94)$ & $7.20(1.70)$ & $7.61(2.01)$ & $8.15(2.12) \mathfrak{E}$ & $<0.01$ \\
\hline GS categorized & & & & & $<0.01$ \\
\hline Slow $(<0,8 \mathrm{~m} / \mathrm{s}), \mathrm{n}(\%)$ & $1885(34.26)$ & $252(12.39)$ & $1060(37.56)$ & $573(88.83)$ & \\
\hline Fast $(\geq 0,8 \mathrm{~m} / \mathrm{s}), \mathrm{n}(\%)$ & $3616(65.74)$ & $1782(87.61)$ & $1762(62.44)$ & $72(11.17)$ & \\
\hline $\mathrm{GS}(\mathrm{m} / \mathrm{s})(\mathrm{SD})$ & $1.0(0.69)$ & $1.06(0.22)$ & $0.87(0.25) ¥$ & $0.53(0.22)^{*} \mathfrak{E}$ & $<0.01$ \\
\hline
\end{tabular}

sample was $1.00 \pm 0.69 \mathrm{~m} / \mathrm{s}$ and was gradually lower according to the installation of the frailty $(\mathrm{p}<0.01)$. In addition, the proportion of the slow elderly increased in this same direction (NF $=12.39 \%, \mathrm{PF}=37.56 \%$ and $\mathrm{FF}=88.83 \%, \mathrm{p}<$ $0.01)$. Further, FF, in addition to walking more slowly, was composed of more women, older individuals and with a higher proportion of falling elderly. And when compared to the other groups, elderly of the FF reported two or more falls in the last year, lower HGS, worse functional performance, less sense of self-efficacy to avoid falls, more depressive symptoms and worse cognitive capacity. All these results are shown in Table 1.

Table 2 was showing older non-frail elderly, with a being a woman, having best HGS and lower IADL impairment increases the risk of being faster.

Table 3 presented the results indicated that PF elderly. Similarly, being a woman, with best HGS, best scores in the IADL questionnaire demonstrated a higher odds ratio of belonging to the group of fast elderly.

Regarding FF, the logistic regression model identified that those with best HGS, reports greater number of falls in the last year had a higher odds ratio to present GS $>0.8 \mathrm{~m} / \mathrm{s}$, compared to those who did not show this characteristic (Table 4).

\section{Discussion}

The main objective of the present study was to categorize and compare groups of non-frail, pre-frail and frail elderly, as well as to analyze the associations between fast or slow GS with clinical, demographic, functional and mental factors from a representative sample of the Brazilian population. The results showed different relationships between GS and the independent variables, in the three levels of frailty.

One variable that is known to influence GS is gender, partly because of the difference in height and muscle strength commonly found between men and women ${ }^{23}$. Moreover, the fact of the female pelvis is wider influences hip movements in the frontal plan, increasing the lateral pelvic inclination, adduction and internal rotation of the hip and valgus knees. Consequently, women tend to walk more slowly, with shorter steps, less range of joint motion and higher 
Table 2. Odds ratio, confidence interval, and statistical significance of factors associated with gait speed bigger than $0.8 \mathrm{~m} / \mathrm{s}$ in the non-frail elderly sample of the Fibra Study $(\mathrm{n}=252)$.

\begin{tabular}{lccc}
\hline \multicolumn{1}{c}{ Variables } & OR & $($ IC95\%) & p-Value \\
\hline Age & 0.84 & $(0.79-0.89)$ & $<0.01^{*}$ \\
Female & 1.58 & $(1.36-1.96)$ & $0.01^{*}$ \\
BMI & 0.84 & $(0.79-0.90)$ & $<0.01^{*}$ \\
HGS & 1.29 & $(1.20-1.39)$ & $<0.01^{*}$ \\
IADL & 1.36 & $(1.22-1.52)$ & $<0.01^{*}$ \\
FES-I Brasil & 0.81 & $(0.77-0.86)$ & $<0.01^{*}$ \\
BMI: Body Mass Index; HGS: Handgrip Strength; IADL: \\
Instrumental Activities of Daily Living; FES-I-Brasil: Falls \\
Efficacy Scale-International. * Significant difference. OR > 1 \\
are associated with increased probability of GS be greater than \\
0.8m/s.
\end{tabular}

Table 3. Odds ratio, confidence interval, and statistical significance of factors associated with gait speed bigger than $0.8 \mathrm{~m} / \mathrm{s}$ in the pre-frail elderly sample of the FIBRA Study $(\mathrm{n}=1060)$.

\begin{tabular}{lccr}
\hline \multicolumn{1}{c}{ Variables } & OR & $($ IC 95\%) & p-Value \\
\hline Female & 1.44 & $(1.30-1.65)$ & $<0.01^{*}$ \\
HGS & 1.37 & $(1.32-1.42)$ & $<0.01^{*}$ \\
IADL & 1.13 & $(1.03-1.23)$ & $0.01^{*}$ \\
FES-I Brasil & 0.75 & $(0.73-0.78)$ & $<0.01^{*}$ \\
\hline
\end{tabular}

BMI: Body Mass Index; HGS: Handgrip Strength; IADL: Instrumental Activities of Daily Living; FES-I-Brasil: Falls Efficacy Scale-International. * Significant difference. OR $>1$ are associated with increased probability of GS be greater than $0.8 \mathrm{~m} / \mathrm{s}$

Table 4. Odds ratio, confidence interval, and statistical significance of factors associated with gait speed bigger than $0.8 \mathrm{~m} / \mathrm{s}$ in the frail elderly sample of the FIBRA Study $(\mathrm{n}=573)$.

\begin{tabular}{lccr}
\hline \multicolumn{1}{r}{ Variables } & OR & $($ IC95\%) & p-Value \\
\hline HGS & 1.48 & $(1.24-1.54)$ & $<0.01^{*}$ \\
Falls & 2.31 & $(2.01-2.99)$ & $0.03^{*}$ \\
BADL & 0.32 & $(0.14-0.75)$ & $0.01^{*}$ \\
FES-I Brasil & 0.58 & $(0.68-0.91)$ & $0.01^{*}$ \\
GDS & 0.71 & $(0.52-0.96)$ & $0.03^{*}$ \\
\hline
\end{tabular}

HGS: Handgrip Strength; BADL: Basic Activities of Daily Living; FES-I-Brazil: Falls Efficacy Scale-International; GDS: Geriatric Depression Scale; MMSE: Mental State Mini-Exam. ${ }^{*}$ Significant difference. OR $>1$ are associated with increased probability of GS be greater than $0.8 \mathrm{~m} / \mathrm{s}$.

cadence $^{24}$. This influence was found in non-frail and pre-frail elderly, and not observed in frail elderly despite the higher prevalence of women.
However, contrary to the literature, data have shown that non-frail and pre-frail women tend to be faster. In this case, it can be assumed that these elderly women, in better health, still tend to preserve their independence through a faster gait. Similarly, one can infer a greater influence of the adverse outcomes in the gait of frail elderly. Likewise, it is suggested that new studies in the future will better investigate the influence of gender on GS and on fragility.

The HGS was one of the variables that showed association with the GS in the three groups. It is known that this measure is associated with global muscle strength in the elderly and that low values represent an increased risk of functional limitation and slow gait ${ }^{25}$. With the aging of the musculoskeletal system, there is a reduction of muscle mass secondary to a decrease in the number of motoneurons, a lower level of physical activity and a decline in protein intake, along with hormonal and inflammatory changes, characterizing sarcopenia. Thus, in the aging process, there is a loss of approximately $30 \%$ of muscular mass between the age of 20 and 80 , more pronounced in the lower limbs, compromising the biomechanics of the gait, with consequent reduction of the length of the pace and the $\mathrm{GS}^{25}$. In addition, there is a non-linear relationship between muscle strength and GS, demonstrating that small increases in muscle strength may substantially increase the GS of frail elderly. However, large increases in muscle strength increase very little the GS of healthy elderly ${ }^{26}$. The findings of the present study corroborate these results, since the HGS was related to the better GS in the three levels of frailty, but with greater odds ratio in the frail elderly, when compared to the pre-frail and non-frail elderly. This observation points to the importance of muscular strength in the process of fragility.

Falls are considered indicators of functional decline and markers of frailty, while gait slowness is able to predict falls, evidencing a bidirectional relationship between these variables ${ }^{27}$. Quach et al. ${ }^{27}$ identified the existence of a nonlinear relationship between the GS and falls, demonstrating extremes, meaning that slower and faster elderly are those who are at a higher risk of falling. This relationship was explained by the fact that the slower elderly are less active, generally sicker and more likely to fall inside the home, while the elderly who are fast are more likely to fall outside the home because they are more exposed to environmental and behavioral risks $^{27}$. In the present study, the report of falls 
in the last year had increased 2.31 times the chance of the frail elderly walk faster. A probable justification for this association to have been verified only in frail elderly may be the fact that it presents a higher proportion of elderly who fall recurrently. As previously reported, gait faster increases the risk of falls, especially outside the home. In this case, failure to investigate the site of falls may have been a limitation of the study and should be investigated in future studies.

Changes inherent to aging may compromise the performance of the elderly in activities of daily living, especially those related to mobility. Katz demonstrated the existence of a hierarchical structure among BADL specific tasks. That is, the elderly with progressive functional decline lose the ability to perform tasks in the reverse order in which they acquired in childhood ${ }^{20,28}$. Lawton and Brody expanded the understanding of functional performance by defining more complex activities such as IADL and, because they require good cognitive functioning, are lost before $\mathrm{BADL}^{28}$. The associations found in the present study evidenced this hierarchical loss of functional abilities, since the elderly of non-frail and pre-frail, with best IADL, presented a greater chance of walking faster.

The greater clinical application of these results indicates the necessity of the measurement of gait speed in the evaluation of the Brazilian elderly in order to prevent future health conditions. However, some limitations of this study should be pointed out. Although an analysis has been made in a large number of Brazilian cities, these data refer to urban populations and cannot be applied to rural populations. Likewise, inferences of causality cannot be made due to the methodological design of the study. The other side, it should be noted that the strength of the study is its population-based design, in the cities. The use of a national urban sample makes the results more generalizable to an elderly urban population of the Brazilian community.

\section{Conclusion}

The mean gait speed of the Brazilian elderly population was different in the three levels of frailty, with non-frail elderly people usually walking faster and, frail elderly in a slower way. The strong association between gait speed, frailty and adverse health outcomes reinforces its primacy as an indicator of the functional health of the elderly. Considering the potential reversibility of some of these variables through therapeutic interventions, it is suggested to observe them with attention in the evaluation and in the treatment focused on the functional improvement in the elderly. 


\section{Collaborations}

RC Guedes, R Dias and LP Lustosa were responsible for the conception, writing, statistical analysis, revision and final approval. AL Neri, E Ferriolli and RA Lourenço were responsible for the conception, research, methodology and final approval.

\section{Acknowledgments}

We thank the Pró-Reitoria de Pesquisa da Universidade Federal de Minas Gerais, Belo Horizonte, MG, Brazil; Conselho Nacional de Desenvolvimento Científico e Tecnológico (CNPq); Fundação de Amparo à Pesquisa do Estado de Minas Gerais (FAPEMIG) and Coordenação de Aperfeiçoamento de Pessoal de Nível Superior (CAPES) for the support of our work.

\section{References}

1. van Kan GA, Rolland Y, Bergman H, Morley JE, Kritchevsky SB, Vellas B. The I.A.N.A Task Force on frailty assessment of older people in clinical practice. $J$ Nutr Health Aging 2008; 12(1):29-37.

2. Xue QL, Bandeen-Roche K, Varadhan R, Zhou J, Fried LP. Initial manifestations of frailty criteria and the development of frailty phenotype in the Women's Health and Aging Study II. J Gerontol A Biol Sci Med Sci 2008; 63(9):984-990.

3. Lang PO, Michel JP, Zekry D. Frailty syndrome: a transitional state in a dynamic process. Gerontology 2009; 55(5):539-549.

4. Fried LP, Ferrucci L, Darer J, Williamson JD, Anderson G. Untangling the concepts of disability, frailty, and comorbidity: implications for improved targeting and care. J Gerontol A Biol Sci Med Sci 2004; 59(3):255263.

5. Fried LP, Tangen CM, Walston J, Newman AB, Hirsch C, Gottdiener J, Seeman T, Tracy R, Kop WJ, Burke G, McBurnie MA, Cardiovascular Health Study Collaborative Research Group. Frailty in older adults: evidence for a phenotype. J Gerontol A Biol Sci Med Sci 2001; 56(3):M146-M156.

6. Fritz S, Lusardi M. White paper: "walking speed: the sixth vital sign”. J Geriatr Phys Ther 2009; 32(2):46-49.

7. Studenski S. Bradypedia: is gait speed ready for clinical use? J Nutr Health Aging 2009; 13(10):878-880.

8. Vermeulen J, Spreeuwenberg MD, Daniels R, Neyens JC, Van Rossum E, De Witte LP. Does a falling level of activity predict disability development in community-dwelling elderly people? Clinical Rehabilitation 2013; 27(6):546-554.

9. Cooper R, Kuh D, Cooper C, Gale CR, Lawlor DA, Matthews F, Hardy R, FALCon and HALCyon Study Teams. Objective measures of physical capability and subsequent health: a systematic review. Age Ageing 2011; 40(1):14-23.

10. van Kan GA, Rolland Y, Andrieu S, Bauer J, Beauchet O, Bonnefoy M, Cesari M, Donini LM, Gillette Guyonnet S, Inzitari M, Nourhashemi F, Onder G, Ritz P, Salva A, Visser M, Vellas B. Gait speed at usual pace as a predictor of adverse outcomes in community-dwelling older people an International Academy on Nutrition and Aging (IANA) Task Force. J Nutr Health Aging 2009; 13(10):881-889.

11. Studenski S, Perera S, Patel K, Rosano C, Faulkner K, Inzitari M, Brach J, Chandler J, Cawthon P, Connor EB, Nevitt M, Visser M, Kritchevsky S, Badinelli S, Harris T, Newman AB, Cauley J, Ferrucci L, Guralnik J. Gait speed and survival in older adults. JAMA 2011; 305(1):50-58.

12. Cesari M. Role of gait speed in the assessment of older patients. JAMA 2011; 305(1):93-94.

13. Silva SL, Neri AL, Ferriolli E, Lourenço RA, Dias RC Phenotype of frailty: the influence of each item in determining frailty in community-dwelling elderly - the FIBRA study. Cien Saude Colet 2016; 21(11):34833492.

14. Ferriolli E, Pessanha FPADS, Moreira VG, Dias RC, Neri AL, Lourenço RA. Body composition and frailty profiles in Brazilian older people: Frailty in Brazilian Older People Study - FIBRA-BR. Arch Gerontol Geriatr 2017; 71:99-104. 
15. Brucki SM, Nitrini R, Caramelli P, Bertolucci PH, Okamoto IH. Suggestions for utilization of the mini-mental state examination in Brazil. Arquivos Neuro-psiquiatria 2003; 61(3B):777-781.

16. Batistoni SS, Neri AL, Cupertino AP. Validity of the Center for Epidemiological Studies Depression Scale among Brazilian elderly. Rev Ssaude Publica 2007; 41(4):598-605.

17. Lustosa LP, Pereira DS, Dias RC, Britto RR, Parentoni NA, Pereira LSM. Tradução e adaptação transcultural do Minnesota Leisure Time Activities Questionnaire em idosos. Geriatria Gerontol 2011; 5(2):57-65.

18. Reuben DB, Laliberte L, Hiris J, Mor V. A hierarchical exercise scale to measure function at the Advanced Activities of Daily Living (AADL) level. J Am Geriatr Soc 1990; 38(8):855-861.

19. Lawton MP, Brody EM. Assessment of older people: self-maintaining and instrumental activities of daily living. Gerontologist 1969; 9(3):179-186.

20. Lino VT, Pereira SR, Camacho LA, Ribeiro Filho ST, Buksman S. Cross-cultural adaptation of the Independence in Activities of Daily Living Index (Katz Index). Cad Saude Publica 2008; 24(1):103-112.

21. Camargos FF, Dias RC, Dias JM, Freire MT. Cross-cultural adaptation and evaluation of the psychometric properties of the Falls Efficacy Scale-International Among Elderly Brazilians (FES-I-BRAZIL). Rev Bras Fisioter 2010; 14(3):237-243.

22. Almeida OP, Almeida SA. Reliability of the Brazilian version of the abbreviated form of Geriatric Depression Scale (GDS) short form. Arq Neuro-psiquiatria 1999; 57(2B):421-426.

23. Almeida OP, Almeida SA. Reliability of the Brazilian version of the abbreviated form of Geriatric Depression Scale (GDS) short form. Arq Neuro-psiquiatria 1999; 57(2B):421-426.

24. Chiu MC, Wu HC, Chang LY. Gait speed and gender effects on center of pressure progression during normal walking. Gait Posture 2013; 37(1):43-48.
25. Kirkwood RN, Gomes HA, Sampaio RF, Furtado SRC, Moreira BS. Spatiotemporal and variavility gait data community-dwelling elderly women from Brazil. Braz J Phys Ther 2016; 20(3):258-66.

26. Cebolla EC, Rodacki ALF, Bento PCB. Balance, gait functionality and strength: comparison between eldely fallers and non-fallers. Braz J Phys Ther 2015; 19(2):146-151.

27. Buchner DM, Larson EB, Wagner EH, Koepsell TD, de Lateur BJ. Evidence for a non-linear relationship between leg strength and gait speed. Age Ageing 1996; 25(5):386-391.

28. Quach L, Galica AM, Jones RN, Procter-Gray E, Manor B, Hannan MT, Lipsitz LA. The nonlinear relationship between gait speed and falls: the Maintenance of Balance, Independent Living, Intellect, and Zest in the Elderly of Boston Study. J Am Geriatr Soc 2011; 59(6):1069-1073.

29. Njegovan V, Hing MM, Mitchell SL, Molnar FJ. The hierarchy of functional loss associated with cognitive decline in older persons. J Gerontol A Biol Sci Med Sci 2001; 56(10):M638-M643.-

Article submitted on 15/10/2017

Approved on 14/09/2018

Final version submitted on 16/09/2018 